\title{
Variation in environmental conditions in a subtidal prey refuge: effects of salinity stress, food availability and predation on mussels in a fjord system
}

\author{
Stephen R. Wing ${ }^{1, *}$, James J. Leichter ${ }^{2}$ \\ ${ }^{1}$ Department of Marine Science, 310 Castle Street, University of Otago, Dunedin 9054, New Zealand \\ ${ }^{2}$ Scripps Institution of Oceanography, University of California at San Diego, 9500 Gilman Drive, La Jolla, California 92093, USA
}

\begin{abstract}
Prey refuges are fundamental structural features in communities. We investigated variability in environmental conditions within a subtidal prey refuge for the blue mussel Mytilus edulis galloprovincialis formed by the persistent low-salinity layer (LSL) in Doubtful Sound, New Zealand. Multi-year observations and fine-scale oceanographic surveys along the axis of Doubtful Sound show strong spatial gradients in salinity, temperature, chlorophyll a ( $\mathrm{chl}$ a) and nitrate concentrations. Mean surface salinity ranged from $~ 5$ in the inner fjord zone to 15 in the mid-fjord, and 25 to 30 in the entrance zone. A marked subsurface maximum in chl a was observed below the LSL at 3 to $7 \mathrm{~m}$ depth. Adult blue mussels were confined to the LSL with a sharp decline in abundance from the entrance to the inner regions of the fjord. In contrast, mussel recruitment was observed both within and below the LSL to $10 \mathrm{~m}$ depth, with highest recruitment in the mid-fjord zone at $6 \mathrm{~m}$ depth. To test whether patterns in growth and survival in the absence of predation were coincident with food supply and salinity stress, we transplanted mussels in predator exclusion cages at depths of 2, 4, 6, and $8 \mathrm{~m}$ within inner, mid-, and entrance fjord zones and measured growth over $213 \mathrm{~d}$. Variation in salinity and temperature, rather than food availability, had the largest impact on mussel growth rates and explained $89 \%$ of the variability in mussel growth. Salinity alone explained $87 \%$ of the variability in mussel growth. Adult survival in the absence of predation did not significantly differ with depth or fjord zone. Environmental stress, primarily in the form of stress associated with low salinity, exerted the greatest influence on growth of mussels within this critical subtidal prey refuge.
\end{abstract}

KEY WORDS: Prey refuge $\cdot$ Subtidal $\cdot$ Food web $\cdot$ Salinity stress $\cdot$ Predation $\cdot$ Mussels $\cdot$ Fiordland

\section{INTRODUCTION}

Refuges from predation play central roles in interand intra-specific interactions (Holt 1977), recruitment dynamics (Menge \& Sutherland 1976), and maintenance of biodiversity in a wide variety of ecosystems (Menge \& Sutherland 1976, Chesson 1986, Sih 1992). Mechanisms for reduction of predation rates in refuges include behaviour of both predators and prey (Sih et al. 1988), temporal variability in predation risk (Sih 1997, Sih et al. 2000), and environmental or physical restrictions on predation (Menge 1978, Petraitis 1990, Robles et al. 1990, 2009). The importance of refuges from predation for maintenance of prey populations has been most extensively described for fish and invertebrate communities in aquatic and marine systems (Sih et al. 1985, Hixon \& Menge 1991, Sih 1992, Hixon \& Beets 1993, Persson 1993, Persson \& Eklöv 1995). Rocky intertidal systems, where wave exposure and desiccation stress limit the ability of predators to venture into the intertidal zone, have also provided classic ecological examples of maintenance of prey populations in refuges (Menge \& Sutherland 1976, Paine 1980). In addition, studies in these systems have highlighted the importance of environmental gradients in mediating the influences of consumers within marine communities and in maintenance of diversity patterns (Menge \& Lubchenco 1981, Menge \& Sutherland 1987). This work 
has been extended to considering ecological effects of physical gradients across estuaries and within the more extensive subtidal zone (Rosenberg \& Möller 1979, Witman \& Grange 1998).

While it is clear that strong predation pressure can restrict prey populations to refuge habitats and increase inter-specific competition among prey, multiple biological and physical gradients can also exist within prey refuges (e.g. Sih 1997). The resulting spatial heterogeneity of environmental conditions can be ecologically important, but difficult to detect from data on prey abundance alone. In essence, the strong effects of predation on prey distribution patterns can mask more subtle yet ecologically important effects of variation in environmental conditions among and within refuge habitats. Studies from a range of ecosystems including aquatic and marine habitats have shown that environmental conditions within predation refuges may be suboptimal for growth, survivorship, or reproduction of prey species relative to conditions outside of refuges if predators were not present (e.g. Hall et al. 1979, Mittelbach \& Chesson 1987, Persson 1993, Persson \& Eklöv 1995 and literature reviewed therein). Fewer studies have examined the importance of spatial variation in environmental conditions within predation refuges. In cases where multiple physical and biological gradients occur within prey refuges, trade-offs are likely to exist between locations that maximize protection from predation yet provide adequate food resources and minimize environmental and physiological stress. Thus, space within prey refuges is likely to be made up of mosaics or gradients of habitats of varying quality for prey populations. Here we describe an experimental and analytical approach to examining the heterogeneity in environmental conditions and their consequences for mussels inhabiting a prey refuge in the shallow rocky subtidal zone in New Zealand fjords.

Fjord systems make up significant portions of the overall coastline of many temperate areas owing to the fjords' complex topography (e.g. in Patagonia, Scandinavia, British Columbia, and New Zealand). They can also be ideal settings in which to examine the physical basis and ecological importance of spatial heterogeneity in environmental conditions within a prey refuge. Strong and predictable vertical gradients produced by hydrographic structure at the scale of 1 to $10 \mathrm{~m}$ are often modulated over a horizontal distance extending tens of kilometres from the inner reaches of the fjords to their entrances along the open coast. The relatively protected waters within fjords frequently allow access by small boats and SCUBA divers and are therefore conducive to detailed subtidal sampling and experimental manipulations that would be impossible along the more wave-exposed open coast, where ecological studies are frequently limited to the intertidal zone.
In Doubtful Sound, New Zealand, a persistent surface low-salinity layer (LSL) is produced by natural run-off and by freshwater output from a large hydroelectric power plant, and provides a subtidal refuge from predation for the blue mussel Mytilus edulis galloprovincialis (Witman \& Grange 1998). Witman \& Grange (1998) demonstrated that at mid-fjord sites, stenohaline predators including the eleven-armed sea star Coscinasterias muricata and the red rock lobster Jasus edwardsii are effectively excluded from the LSL. The resulting prey refuge within the LSL harboured dense aggregations of adult $M$. edulis galloprovincialis, and predators rapidly consumed adult mussels that were experimentally moved below the LSL. Witman \& Grange (1998) concluded that the observed distribution pattern of adult blue mussels was largely driven by avoidance of the LSL by the relatively large and conspicuous predators in the system. Communitylevel effects of the LSL were further illuminated by Smith \& Witman (1999), who demonstrated that at midand entrance fjord sites, salinity provided the physical basis for a division between diverse suspension-feeding communities below the LSL and communities dominated by mussels, barnacles, and macroalgae within the LSL.

While the exclusion of stenohaline predators from areas of low salinity can provide a refuge from predation for mussels, exposure to salinities below 5 to 9, particularly in combination with elevated temperatures, can also induce significant physiological stress (Fox 1941, Bohle 1972, Stickle \& Sabourin 1979, Braby \& Somero 2006), reduced growth rates, and increased mortality in blue mussels Mytilus spp. Early life history stages are particularly sensitive to these low salinity conditions (Qiu et al. 2002). Variability in the quantity and quality of seston across these environments may also limit growth and survivorship, and may be an important environmental influence in subtidal refuge environments. A wealth of physiological and environmental studies on the genus Mytilus indicate that growth rates respond positively to concentrations (e.g. Coe \& Fox 1944) and quality of seston (Bayne et al. 1993).

The large input of freshwater into Doubtful Sound from the Manapouri hydroelectric power plant has resulted in extended periods of very low salinity (0 to 5) within the surface waters throughout the inner portion of the fjord, and significant changes in the shallow water communities (Batham 1965, Boyle et al. 2001, Rutger \& Wing 2006), including large reductions in abundances of the common infaunal bivalves Paphes australis and Austrovenus stutchburyi (Tallis et al. 2004, McLeod \& Wing 2008). The LSL also strongly limits food availability for bivalves. Phytoplankton production within the LSL, which is high in silicon (Si), is limited by supply of macronutrients (nitrogen, $\mathrm{N}_{\text {; }}$ phos- 
phorus, P) that originate in the underlying seawater layer. Consequently, peak production of phytoplankton, particularly diatoms, typically occurs in the narrow band of mixing at the base of the LSL where high concentrations of $\mathrm{Si}, \mathrm{N}$ and $\mathrm{P}$ mix (Goebel et al. 2005). Thus, the subtidal refuge from predation for Mytilus edulis galloprovincialis associated with the LSL likely also contains gradients in environmental conditions, both in terms of salinity stress and food availability. These observations present an interesting question: What are the consequences of spatial gradients in salinity stress and food availability within the LSL predation refuge along the length of the fjord for the growth, survivorship, and distribution of blue mussels?

To answer this question, we measured hydrographic patterns throughout Doubtful Sound and examined the relationship between abundance and recruitment of Mytilus edulis galloprovincialis across depths within and below the LSL at multiple sites along a $30 \mathrm{~km}$ gradient spanning the inner, mid, and entrance regions of the fjord. We then conducted a multi-site, depth-stratified, predation exclusion experiment to assess the relative importance of temperature, salinity, and chlorphyll a ( $\mathrm{chl} a)$ concentration for the growth and survivorship of mussels in the absence of predation along the extent of the fjord.

\section{MATERIALS AND METHODS}

Site description. Doubtful Sound is a large, deep-water fjord along the southwestern coast of the south island of New Zealand, in a region known as Fiordland. As described in the Introduction, the input of freshwater from the Manapouri hydroelectric power plant strongly influences the dynamics of the LSL, creating strong gradients in salinity conditions and depth of the LSL along the length of the fjord. LSL dynamics are also a natural feature of this environment and are observed in other fjords throughout Fiordland (Stanton \& Pickard 1981). The subtidal environment within the fjord is characterized by steep rock walls as well as soft sediment habitats and riverine deltas. These habitats harbour abundant and diverse communities of benthic sessile and mobile invertebrates and fish. Detailed descriptions of diversity patterns for the rock wall communities can be found in Smith \& Witman (1999).
Oceanographic sampling. An 8 yr time series of CTD casts at the inner fjord, mid-fjord, and entrance sites (Fig. 1) was used to characterise the climatological water column conditions for each of these 3 zones within the fjord. Salinity and temperature profiles were collected from the surface to $50 \mathrm{~m}$ depth in each fjord zone during each year from 1998 to 2006 using a Seabird SBE-19 pumped CTD profiler with attached chl a fluorometer. Data were post-processed to $0.5 \mathrm{~m}$ depth bins using standard Seabird processing algorithms. Average, minimum, maximum, and standard error of salinity were calculated for the study period (1998 to 2006) for each $0.5 \mathrm{~m}$ depth bin through the water column.

Fine-scale replicate oceanographic surveys were conducted from a small boat along the $35 \mathrm{~km}$ axis of Doubtful Sound on 13 and 26 July 2006. In each survey, 10 oceanographic stations spaced at 3 to $5 \mathrm{~km}$

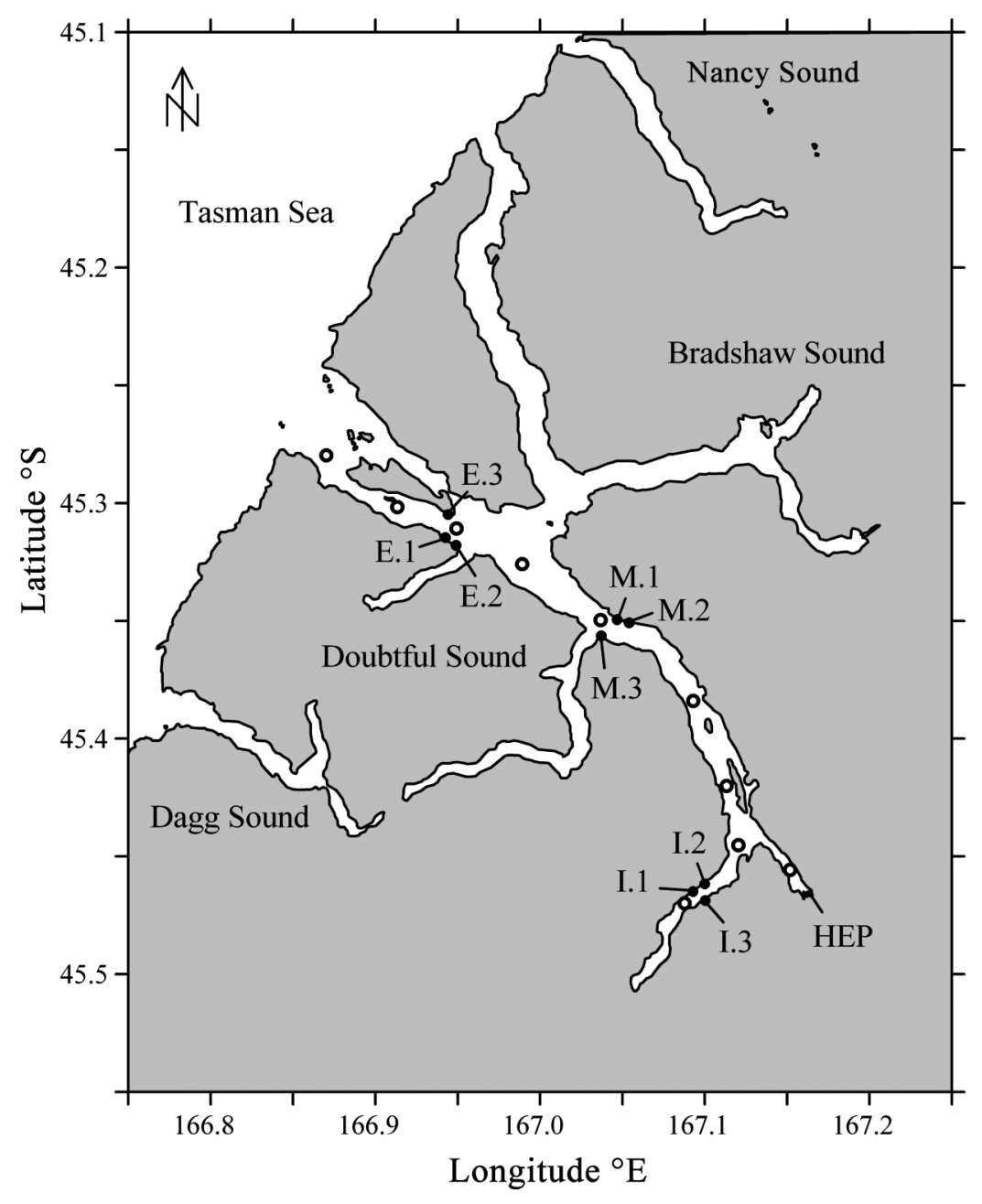

Fig. 1. Map of Doubtful Sound, New Zealand, with locations of study sites displayed as $\bullet$ : E.1 to E.3 are entrance sites, M.1 to M.3 are mid-fjord sites, and I. 1 to I.3 are inner fjord sites. o depict location of CTD casts. The outlet of the Manapouri hydroelectric power plant is marked with HEP 
intervals were sampled from the inner reaches of Doubtful Sound to the open coast (Fig. 1). At each station, a vertical hydrocast of temperature, conductivity, chl $a$, and nitrate concentration was collected from the surface to $50 \mathrm{~m}$ depth using a factory-calibrated, pumped Seabird SBE-19 CTD profiler with attached Wetstar fluorometer and Satlantic ISUS photometric nitrate sensor. The instrument package sampled at $0.5 \mathrm{~s}$ intervals and was lowered at $\sim 0.5 \mathrm{~m} \mathrm{~s}^{-1}$. Data were post-processed and averaged in $1 \mathrm{~m}$ vertical bins using standard Seabird processing algorithms on the data from the downward travelling portion of each cast. The data were subsequently interpolated onto a regularly spaced grid and plotted as horizontal sections along the axis of the fjord using a krieging algorithm in Matlab (MathWorks). Three discrete water samples for cross calibration of the optical nitrate sensor were collected using clean 1.2 1 Niskin bottles at the surface, in the LSL, and at $10 \mathrm{~m}$ depth at each sampling station. Nitrate concentration in 2 replicate $60 \mathrm{ml}$ subsamples from each Niskin bottle was subsequently quantified using a Lachat Quickchem 8000 automated ion analyzer with a copper cadmium reduction column. Data from the CTD casts at 3 inner, 3 mid-, and 3 entrance fjord stations were used to calculate average temperature, salinity, chl $a$, and nitrate for depth bins corresponding to depths of the mussel transplant experiment (see below) at 0-2 m, 2-4 m, 4-6 $\mathrm{m}$, and 6-8 $\mathrm{m}$ below mean high water.

Mussel abundance survey. The percent cover of mussels was surveyed during summer (January to February 2004) using a stratified random sampling design at replicate locations at inner, mid, and entrance sites within Doubtful Sound (Fig. 1). At each site, 12 replicate $0.25 \mathrm{~m}^{2}$ quadrats with $25 \mathrm{~cm}^{2}$ grids were positioned at $2 \mathrm{~m}$ depth intervals from the high tide line to $10 \mathrm{~m}$ depth. For each quadrat, percent cover of Mytilus edulis galloprovincialis was quantified by counting the number of grid squares that were occupied by adult mussels, and by searching for new recruits. Averages and SE of percent cover were calculated for each depth and zone (inner, mid, and entrance fjord). Careful notes were taken on the presence of visible, new recruits (3 to $10 \mathrm{~mm}$ ) in the population. A 1-way ANOVA was used to test for differences in mean mussel percent cover among fjord zones at each depth where mussels were found. Zone was treated as a fixed factor, and percent data were arcsine transformed prior to analysis. A Tukey's post hoc test was used to compare differences among groups in cases where the null hypothesis was rejected.

Mussel recruitment collectors. Spatial variability in recruitment of Mytilus edulis galloprovincialis along the length of the fjord was measured using artificial settlement collectors deployed from late spring to summer (October to February 2004) during the peak season of mussel settlement (McDonald 2003). Three vertical arrays of recruitment collectors were deployed at each of the inner, mid-, and entrance fjord zones at depths of $2,4,6$, and $8 \mathrm{~m}$ below mean high water within each region ( 3 vertical arrays per zone $\times 3$ zones $\times 4$ depths $=36$ collectors $)$. Collectors were constructed of looped vinyl Nomad ${ }^{\mathrm{TM}}$ cushion mat cut into $10 \mathrm{~cm}$ squares, and deployed and recovered by SCUBA divers. Following retrieval, collectors were examined under dissecting microscopes at the Portobello Marine Laboratory, University of Otago for all newly settled mussel recruits. Recruitment data (ind. $\mathrm{cm}^{-2}$ ) were transformed by $x^{0.25}$ to achieve normality, and a 2-way ANOVA was used to test for differences among depths and fjord zones. Depth and Zone were treated as fixed factors in the ANOVA model.

Mussel transplant experiment. Mytilus edulis galloprovincialis were collected at an entrance fjord site on 24 July 2006, maintained in seawater for initial size measurements and transplanted to 3 replicate experimental sites at each of the inner, mid-, and entrance fjord regions on 26 July 2006 (Fig. 1). At each transplant site, a $10 \mathrm{~m}$ long line was stretched taut vertically between stainless steel bolts anchored to the rock substrate at the high tide mark and at $10 \mathrm{~m}$ depth. Predator exclusion cages made of Nytex plastic mesh $(20 \times$ $10 \mathrm{~cm}$ with $10 \mathrm{~mm}$ mesh size) were attached to each line at depths of $2,4,6$, and $8 \mathrm{~m}$. Each cage contained $7 \mathrm{M}$. edulis galloprovincialis randomly selected from a size range of 35 to $51 \mathrm{~mm}$ shell length $(7$ mussels per cage $\times 4$ cages per line $\times 3$ lines per fjord zone $\times 3$ regions $=252$ individuals in 36 cages). The initial maximum extent of the shell of each mussel was carefully marked on one valve margin with a small triangular file so that growth increment could be measured on retrieval of the experiment. Individual temperature recorders (HOBO Temp; Onset Computers) were attached to each mussel cage and programmed to sample at $30 \mathrm{~min}$ intervals throughout the growth experiment.

The vertical lines and all mussel cages were retrieved after 213 d on 24 February 2007. The 7 mo period of this growth rate experiment spanned the most productive spring and summer months, when chl $a$ and seston concentrations are highest below the LSL (Goebel et al. 2005). Growth increments on the mussel shells were measured as the minimum distance from the new shell extent to the initial file mark. The integrity of each cage for retaining mussels was confirmed and mortality was recorded based on numbers of live mussels remaining in each cage. Growth data from increments at the shell margin were normalized by dividing the change in length by the average shell length during the experimental period. Temperature 
records from each cage were used to calculate average temperature across the experimental period for each depth and fjord region.

Data analysis of mussel transplant experiment. We used a 2-way ANOVA to test for significant effects of fjord zone (inner, mid, and entrance) and depth $(2,4,6$, and $8 \mathrm{~m}$ ) on mean mussel survival and mean normalised growth increment. Depth and Zone were treated as fixed factors, and replicate cages on the 3 lines within each zone and depth were treated as random factors. Data distributions were tested for normality and heterogeneity of variance among treatments prior to ANOVA. Where ANOVA indicated significant effects of the main factors, Tukey's post hoc pair-wise comparisons were conducted among depths and zones. The relationships between depth- and regionspecific mussel growth and average salinity, temperature, and chl a were examined using a series of leastsquares linear models (see Table 1) incorporating all possible linear combinations of the explanatory variables. We then used corrected Akaike's Information Criterion $\left(\mathrm{AIC}_{\mathrm{c}}\right)$ to rank the explanatory power of salinity, temperature, and chl a effects on mussel growth (see Table 1), based on these combined model fits (Anderson et al. 2001, Anderson \& Burnham 2002, Burnham \& Anderson 2002). Formulae for $\mathrm{AIC}_{\mathrm{c}}$ are provided in Anderson et al. (2001). A least-squares linear model framework was used to test for interactions and collinearity among the explanatory variables.

\section{RESULTS}

\section{Oceanographic sampling}

Climatological conditions at the inner, mid-, and entrance fjord zones revealed a consistent gradient in the LSL along the length of Doubtful Sound. Fig. 2 shows the multi-year mean, maximum, minimum, and variance in salinity across depths for each of the 3 fjord zones. Mean surface salinities were approximately 5 , 12 , and 15 at the inner, mid, and entrance zones respectively. Salinity stratification persisted to $5 \mathrm{~m}$ depth at the inner fjord zone, while at the mid- and entrance zones the LSL was consistently thinner, and the difference between mean salinity at the surface and at $5 \mathrm{~m}$ depth was smaller than at the inner zone (Fig. 2).

The fine-scale oceanographic survey on 26 July 2006 illustrated several important features of the LSL along the axis of Doubtful Sound (Fig. 3). Strong stratification of temperature and salinity was evident with a cold LSL occupying the top 1 to $5 \mathrm{~m}$ of the water column. Surface salinity $<10$ was observed at the inner fjord stations, while surface salinity was $\sim 15$ in the mid-fjord zone and
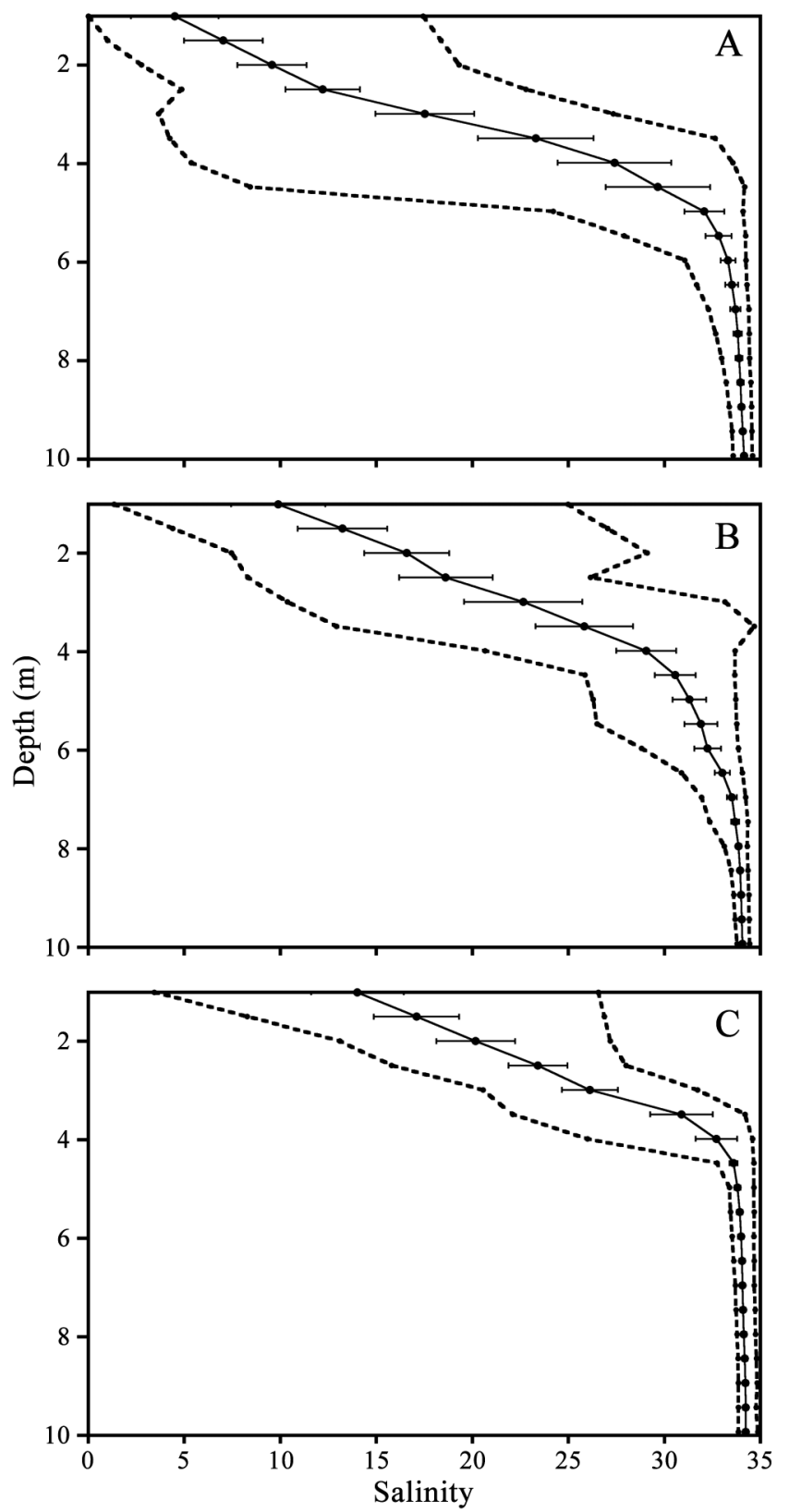

Fig. 2. Average $\left( \pm \mathrm{SE}_{\text {; }}\right.$ solid line $)$, maximum, and minimum salinity (dashed lines) at different depths at the (A) inner fjord site, (B) mid-fjord site, and (C) entrance fjord site from 1998 to 2006

increased to 25 at the entrance stations. These patterns are consistent with previous climatological records and longer term observations of the LSL (Stanton \& Pickard 1981, Gibbs et al. 2000). A distinct chl a maximum was evident below the LSL, indicating high concentrations of phytoplankton at $\sim 3$ to $7 \mathrm{~m}$ depth, consistent with previous observations (Goebel et al. 2005) (Fig. 3). Nitrate concentration increased with increasing depth, varying from 4 to $10 \mu \mathrm{mol} \mathrm{l}^{-1}$, and was highest in the deep water at the inner fjord stations. 


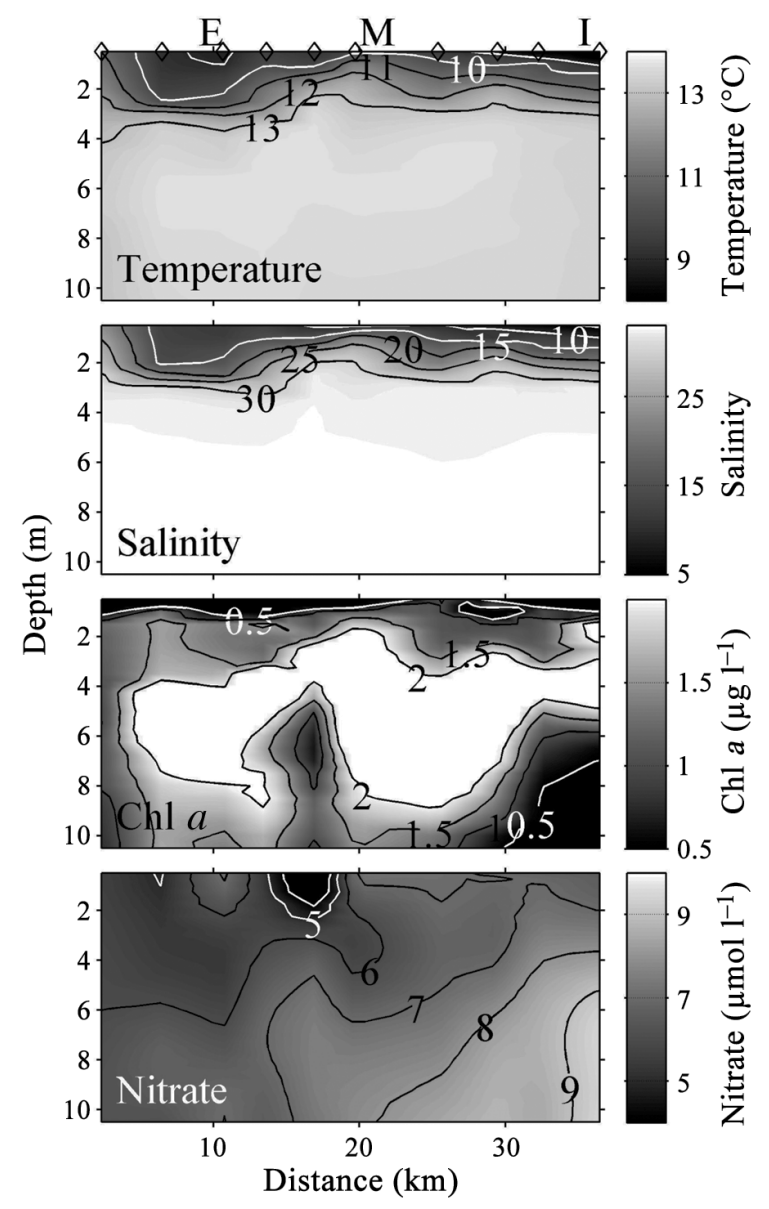

Fig. 3. Contour plots of temperature, salinity, chl a concentration, and nitrate concentration as functions of depth and distance along the axis of Doubtful Sound on 26 July 2006. Distance is given from the location of the first CTD cast near the fjord entrance (see Fig. 1). Top panel: $\diamond=$ location of the 10 CTD sampling stations; E, M, and I = locations of the Mussel transplant experiment sites at the entrance, mid-, and inner fjord locations, respectively

\section{Abundance survey and recruitment data}

Adult Mytilus edulis galloprovincialis percent cover varied significantly among fjord zones. Mussels were absent at all depths within the inner fjord, and were absent below the LSL for the mid- and entrance zones. Mean percent cover at $2 \mathrm{~m}$ depth ranged from 0 at the inner zone to $18 \%$ at the mid- and $55 \%$ at the entrance sites. ANOVA indicated significant differences among fjord zones at $2 \mathrm{~m}$ depth (model $\mathrm{r}^{2}=0.97, F_{2,6}=106.75$, $\mathrm{p}=0.0001$ ). Tukey's post hoc tests indicated significant differences in mean percent cover between each of the fjord zones (Fig. 4A). In contrast to the adult distributions, mussel recruitment was observed at all depths and all fjord zones (Fig. 4B). Highest recruitment, with a distinct maximum of 1.9 mussels $\mathrm{cm}^{-2}$, was observed
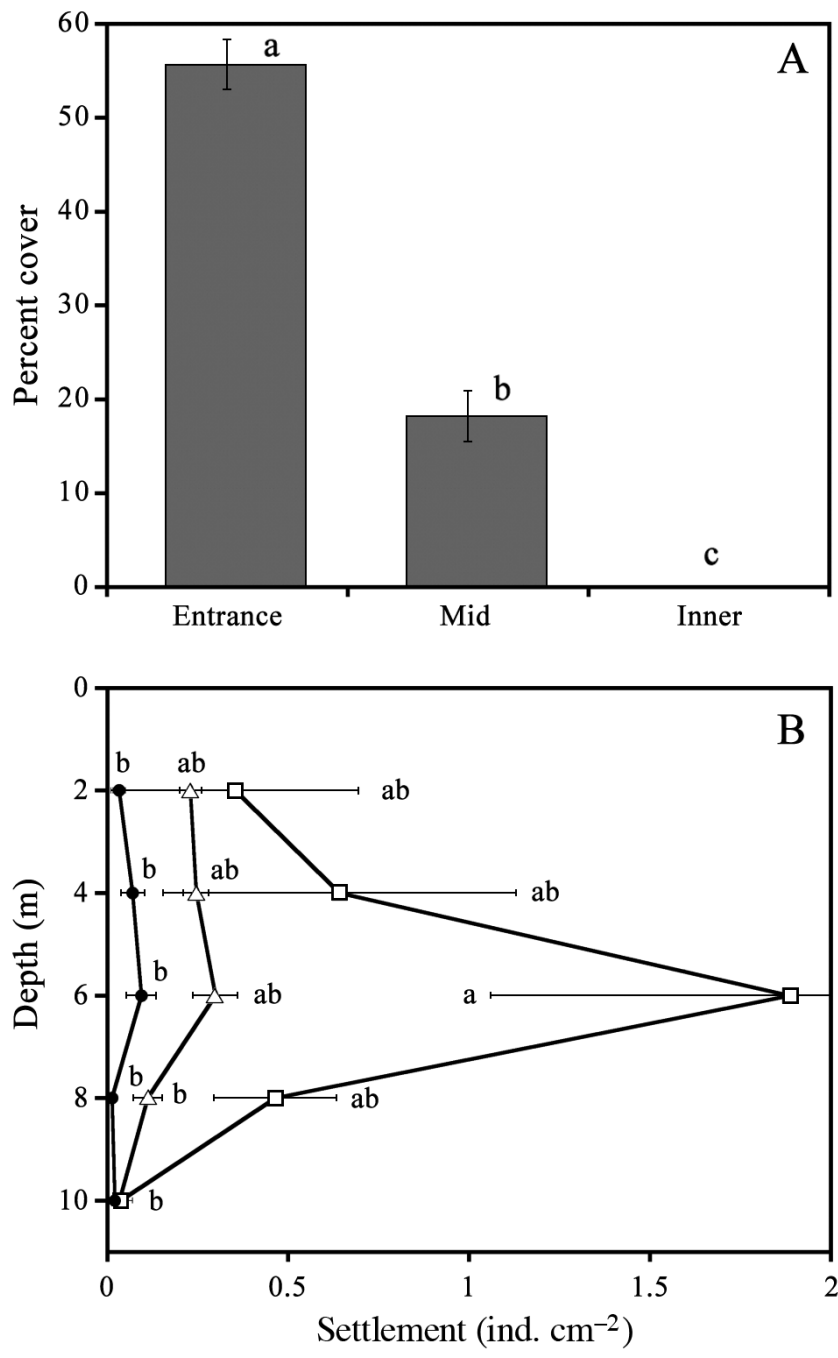

Fig. 4. Mytilus edulis galloprovincialis. (A) Average ( $\pm 1 \mathrm{SE}$ ) percent cover of adults at 0 to $2 \mathrm{~m}$ depth below mean high water in the 3 fjord zones. Adult mussels were not found below $2 \mathrm{~m}$ depth, and therefore data for those depths are not plotted. (B) Average mussel recruitment $\mathrm{cm}^{-2}$ in $5 \mathrm{mo}$ at different depths in inner $(\bullet)$, mid- $(\square)$, and entrance $(\Delta)$ fjord regions. Letters indicate results of Tukey's post hoc comparisons. Groups not sharing the same letter are significantly different $(p<0.05)$

at $6 \mathrm{~m}$ depth at the mid-fjord zone. Recruitment varied from 0.03 to 0.30 mussels $\mathrm{cm}^{-2}$ across depths at the entrance and inner fjord zones. ANOVA on the recruitment data indicated significant effects of both depth and zone (model $\mathrm{r}^{2}=0.61, F_{14,30}=3.32, \mathrm{p}=0.0028$ ), and no significant interaction effect between Depth and Zone $(p=0.30)$. Tukey's post hoc comparisons indicated that among zones recruitment was significantly lower at the inner zone than the mid- or entrance zones, and among dephs, settlement in the $6 \mathrm{~m}$ midzone was higher at all depths in the inner zone and at 8 to $10 \mathrm{~m}$ in the entrance zone (Fig. 4B). 


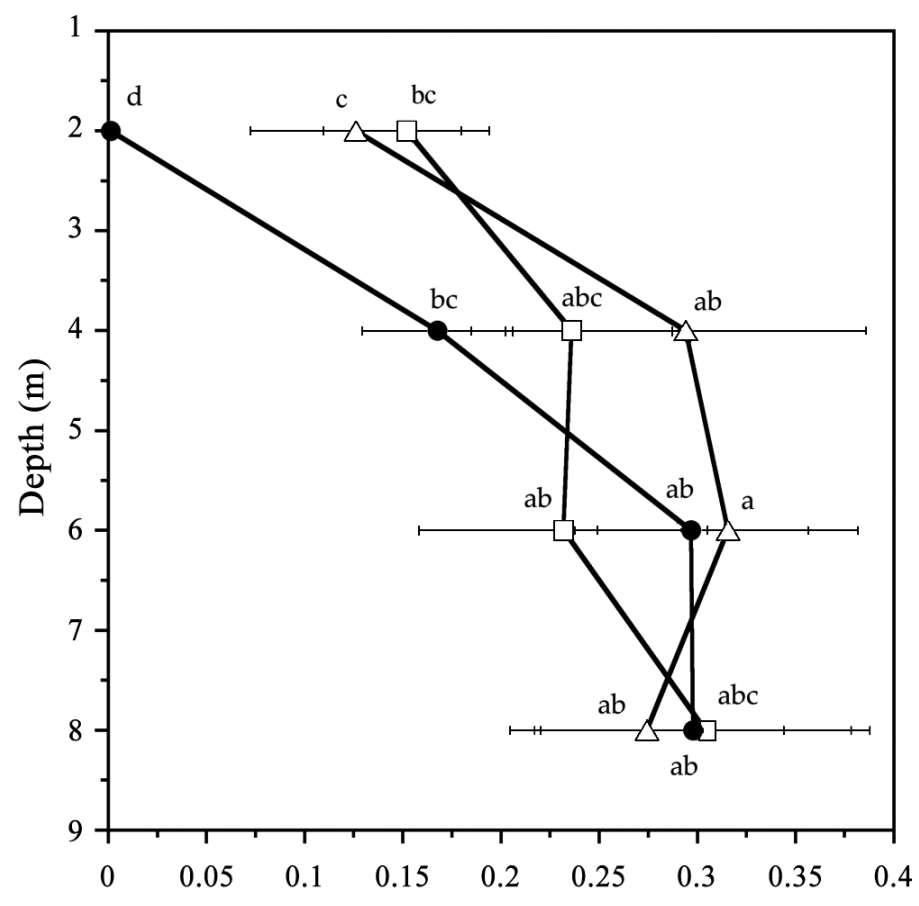

Growth (Change in shell length/Avg shell length)

Fig. 5. Mytilus edulis galloprovincialis. Average ( \pm 1 SE) mussel growth rate at different depths in inner $(\bullet)$, mid $(\square)$, and entrance $(\Delta)$ fjord regions. Letters indicate results of Tukey's post hoc comparisons. Groups not sharing the same letter are significantly different $(\mathrm{p}<0.05)$. Avg: average

\section{Mussel survivorship and growth rates}

All 36 predator exclusion cages were retrieved and Mytilus edulis galloprovincialis survivorship ranged from 33 to $100 \%$ across the experimental cages. Cages with total mortality were excluded from the analysis (Clark et al. 2008), however replication was preserved at all levels. ANOVA detected no significant differences in survivorship among depths and zones (model $\mathrm{r}^{2}=0.38, F_{11,142}=2.25, \mathrm{p}=0.1$ ). Mussel growth rates were positive in all fjord zones and depths except for the shallowest depth $(2 \mathrm{~m})$ at the inner sites (Fig. 5). Fractional growth rates, expressed as change in shell length over average shell length, varied from 0.15 to 0.3 . ANOVA indicated significant differences in mean growth rates among both depths and zones (model $\mathrm{r}^{2}=$ $0.48, F_{11,142}=12.0, \mathrm{p}=0.0001$ ) and a significant interaction effect between Depth and Zone $(p=0.03)$ indicating variation in the effect of depth among fjord zones. Tukey's post hoc comparisons showed that growth was lower at $2 \mathrm{~m}$ than at all deeper depths in both the inner and entrance fjord zones, and that growth was significantly greater at the entrance and mid-zones than at the inner zone within the $2 \mathrm{~m}$ depth stratum (Fig. 5).

The least-squares linear models for mussel growth versus temperature, salinity, and chl a concentration indicated that collectively, these environmental variables explained up to $89 \%$ of the variability in mussel growth across depths and fjord zones (Table 1A). Tests for interactions among the explanatory variables indicated that each variable was independent in the models. AIC analysis demonstrated that salinity was the dominant variable contributing to these models (Table 1). Salinity from the fine-scale survey alone explained $87 \%$ of the variance in mussel growth (Table 1, Fig. 6). Similar results were obtained for AIC using the multi-year climatological data set; in this case, site-specific mean salinity explained $91 \%$ of the variability in mussel growth (Table 1B).

\section{DISCUSSION}

This study demonstrates the importance of spatial variation in environmental conditions within a refuge from predation and illustrates an analytical method for distinguishing the relative impact of physical factors influencing the growth of a prey species. In Doubtful Sound, the 


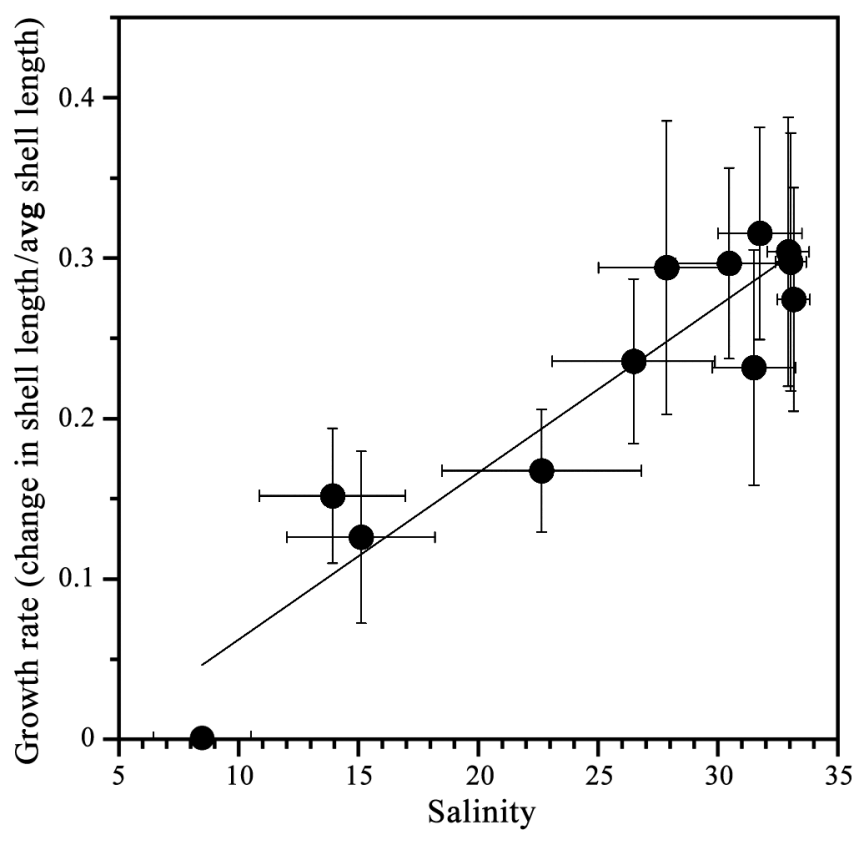

Fig 6. Relationship between average salinity and average growth of Mytilus edulis galloprovincialis for each experimental cage treatment. Growth rate was calculated as change in shell length after 7 mo divided by average (avg) shell length ( $\mathrm{n}=7$ mussels). Error bars represent \pm 1 SE for mean salinity and growth calculated in each of 4 depths $\times 3$ fjord zones $(\mathrm{n}=12)$. Type II linear regression line is drawn (Growth Rate $=0.01185 \times$ Salinity $^{-0.079}, \mathrm{r}^{2}=0.94, \mathrm{p}<0.0001$ )

growth rate of the blue mussel Mytilus edulis galloprovincialis was strongly influenced by spatial variation in salinity stress across fjord zones. Low salinity likely acts as a physiological stress that retards mussel growth at shallow depths, especially in the persistent low salinity conditions in the inner reaches of the fjord. This strong effect of salinity appears to be significantly larger than the effects of food availability, as indicated by water column chl a concentrations, in the system. Adult mussel abundance was largely restricted to the LSL. However, mussel recruitment was observed across depths both within and below the LSL and growth rates for mussels protected from predation were greatest below the LSL, at depths of 4 to $8 \mathrm{~m}$. Thus, one of the consequences of the mussels being confined to the LSL prey refuge is a decrease in realised productivity of the population that might otherwise be possible in the absence of predation.

Adult abundance of Mytilus edulis galloprovincialis in Doubtful Sound was also strongly skewed to the fjord entrance zone. Salinity in the entrance zone ranged from 16 to 34, and mussel beds were confined to the LSL in the upper $3 \mathrm{~m}$ of the water column. In the mid-fjord water column, stratification was greater than at the entrance sites, with salinity ranging from 8 to 20 and the abundance of mussels being markedly lower than at the entrance fjord sites. The water column was most highly stratified in the inner fjord zone, where very low surface salinity conditions ( 0 to 5 ) occured frequently, and adult mussels were rare. Salinity stress is known to directly influence the heart rate and metabolism of $M$. edulis galloprovincialis; at $14^{\circ} \mathrm{C}$, heart rate drops precipitously at salinities below 8.9 (Braby \& Somero 2006). These conditions occur regularly in the inner fjord areas, where we observed low or zero growth rates in the 7 mo experimental period. In these inner fjord regions, the strong stratification in the water column results in an extremely narrow zone where salinity is high enough to support mussels but low enough to exclude predators. Thus, the refuge all but disappears for $M$. edulis galloprovincialis as they are caught between a high predation zone of bare rock and coralline pavement, and a LSL where it is physiologically difficult to maintain osmolarity. These combined effects result in very low abundance of mussels in the inner fjord.

The patterns of adult blue mussel abundance contrasted with patterns of recruitment among fjord zones. Whereas adult distributions were skewed toward the entrance sites and within the LSL, mussel recruitment was highest in the mid-fjord zone below the LSL (6 to $8 \mathrm{~m}$ ) and within the subsurface peak in chl a concentration. In the entrance zone, recruitment was more uniformly distributed across depths from the surface to $8 \mathrm{~m}$. Although recruitment was lower in the inner fjord zone, larvae did settle there, and highest recruitment rates were observed at 4 to $6 \mathrm{~m}$ depth, below the LSL. The disparity between patterns of recruitment and adult abundance are likely explained by the strong effects of differential mortality that were observed by Witman \& Grange (1998). Further, the absence of small juvenile mussels below the LSL suggests that the effects of predation occur early in the life history of mussels rather than in the adult stage, as observed in manipulative experiments: Witman \& Grange (1998) observed that adult Mytilus edulis galloprovincialis were quickly preyed upon when transplanted below the LSL in the mid-fjord region of Doubtful Sound. High rates of predation on adult mussels by the rock lobster Jasus edwardsii and the sea star Coscinasterias muricata were observed in the 'echinoderm zone' below the LSL. While these species undoubtedly are important predators of adult mussels, the present study suggests that the most important period for predation may be more closely following settlement when mussels are available for a wide variety of small predators. Small predators include a suite of species occupying the shallow depths of the fjord such as the sea star Patiriella regularis, the small wrasse Notolabrus celidotus, and the sea urchin Evechinus chloroticus. These abun- 
dant, small predators may be more important in structuring the observed distribution of adult mussels than the larger, conspicuous predators such as J. edwardsii and C. muricata. This idea is corroborated by work of McDonald (2003), who implemented a predation exclusion experiment with fine-meshed $(5 \mathrm{~mm})$ cages deployed below the LSL. Newly settled mussels experienced $100 \%$ mortality in areas exposed to predation, while the caged treatments had higher rates of survival (McDonald 2003). Juvenile mussels are also more sensitive to salinity stress than adults (Qiu et al. 2002).

The results of the least-squares linear models of mussel growth rates in relation to salinity, temperature, and chl a concentration demonstrate the strong covariability of growth with salinity and temperature. Here, $89 \%$ of the variability in growth rate was explained by salinity and temperature. Akaike's Information Criteria applied to a combined suite of models demonstrate that factor weightings are highest for salinity and temperature, proxies for physiological stress, relative to chl a concentration, a proxy for food availability. These results support the idea that environmental conditions associated with physiological stress have the strongest influence on growth within the LSL prey refuge. As active suspension feeders on phytoplankton, mussels capture primary biological production from the water column, and as prey for a range of mobile invertebrate and fish, they represent an important link between water column production and the benthic food web. Experimental results and statistical analyses allow us to distinguish the sources of variation in environmental conditions within the prey refuge and provide a context for considering the ecosystem level consequences of alterations to physical gradients within this system.

Environmental conditions play a critical role in prey refuges. By their nature, these refuges often reflect regions that are either inaccessible to colonisation by predators (Polis \& Hurd 1995) or unsuitable because of high wave action (Menge 1978), desiccation (Robles et al. 1990), or salinity stress (Witman \& Grange 1998). In the cases where refuges are maintained by environmental stressors, prey species are typically living in harsh environments, and the refuges may be on the extremes of physiological tolerance for the prey species, while being beyond those of predators. In the present example, there is clear evidence that human alterations to the environment (the large input of fresh water associated with the hydroelectric power plant) result in extreme low salinity conditions that effectively exclude mussels from the inner zone of the fjord. In this altered habitat, the lack of a shallow subtidal bivalve community has important consequences for benthic-pelagic coupling and food web structure (Rutger \& Wing 2006, McLeod \& Wing 2008). In those regions where mussels do persist in the subtidal prey refuge, they provide important fluxes of carbon in the form of food for benthic fish (Rodgers \& Wing 2008) and the red rock lobster (Jack et al. 2009) as well as particles (pseudofeces and waste) to the underlying suspension feeding community.

Acknowledgements. We thank S. McDonald, L. Jack, S. Rutger, E. Zydervelt, R. McLeod, H. Bowman, D. Stokes, G. Deane, and A. Lewis for assistance with the present study. S. Genovese and P. Petraitis provided valuable comments on the manuscript. Monetary and logistic support was provided by the Royal Society of New Zealand's Marsden Fund to S.R.W. (UO-00213), the Department of Marine Science at the University of Otago, and the Scripps Institution of Oceanography Associates and the Academic Senate of the University of California at San Diego to J.J.L.

\section{LITERATURE CITED}

Anderson D, Burnham K (2002) Avoiding pitfalls when using information-theoretic methods. J Wildl Manag 66:912-918

Anderson D, Link W, Johnson D, Burnham K (2001) Suggestions of presenting the results of data analysis. J Wildl Manag 65:373-378

Batham E (1965) Rocky shore ecology of a southern New Zealand fjord. Trans R Soc NZ 6:215-227

Bayne B, Iglesias J, Hawkins A, Navarro E, Heral M, DeslousPaoli J (1993) Feeding behaviour of the mussel, Mytilus edulis: responses to variation in quality and organic content of the seston. J Mar Biol Assoc UK 73:813-829

Bohle B (1972) Effects of adaptation to reduced salinity on filtration activity and growth of mussels (Mytilus edulis). J Exp Mar Biol Ecol 10:41-49

Boyle M, Jillett J, Mladenov P (2001) Intertidal communities in Doubtful Sound, New Zealand: changes over time. NZ J Mar Freshw Res 35:663-673

> Braby CE, Somero GN (2006) Following the heart: temperature and salinity effects on heart rate in native and invasive species of blue mussels (genus Mytilus). J Exp Biol 209:2554-2566

Burnham K, Anderson D (2002) Model selection and multimodel inference: a practical information-theoretic approach, 2nd edn. Springer-Verlag, New York, NY

Chesson P (1986) Environmental variation and the co-existence of species. In: Diamond J, Case T (eds) Community ecology. Harper \& Row, New York, NY, p 240-256

Clark A, Zydervelt E, Wing S (2008) Modelling count and growth data with many zeros. J Exp Mar Biol Ecol 365: $86-95$

> Coe W, Fox D (1944) Biology of the California sea-mussel (Mytilus californianus). III. Environmental conditions and rate of growth. Biol Bull (Woods Hole) 87:59-72

- Fox D (1941) Changes in the tissue chloride of the California mussel in response to heterosmotic environments. Biol Bull (Woods Hole) 80:111-129

Gibbs M, Bowman M, Dietrich D (2000) Maintenance of near surface stratification in Doubtful Sound, a New Zealand fjord. Estuar Coast Shelf Sci 51:683-704

Goebel N, Wing S, Boyd P (2005) A mechanism for onset of diatom blooms in a fjord with persistent salinity stratification. Estuar Coast Shelf Sci 64:546-560

Hall D, Warner E, Gillian J, Mittelbach G and others (1979) Diel foraging behavior and prey selection in the golden 
shiner (Notemigonus crysoleucas). J Fish Res Board Can 36:1029-1039

Hixon MA, Beets JP (1993) Predation, prey refuges, and the structure of coral-reef fish assemblages. Ecol Monogr 63: $77-101$

Hixon MA, Menge BA (1991) Species diversity: prey refuges modify the interactive effects of predation and competition. Theor Popul Biol 39:178-200

Holt RD (1977) Predation, apparent competition, and the structure of prey communities. Theor Popul Biol 12: 197-229

Jack L, Wing SR, McLeod RJ (2009) Evidence of prey base shifts in rock lobsters (Jasus edwardsii) in response to habitat conversion: implications for efficacy of newly established marine reserves in Fiordland. Mar Ecol Prog Ser 381:213-222

McDonald S (2003) Spatial variability in recruitment of sessile organisms: the effects of a low-salinity gradient, grazing and predation on subtidal community structure along the Doubtful Sound complex, Fiordland, New Zealand. MSc thesis, University of Otago

McLeod R, Wing S (2008) Influences of freshwater input on infaunal bivalves: population response to an altered salinity regime. Estuar Coast Shelf Sci 78:529-540

Menge BA (1978) Predation intensity on a rocky intertidal community: effect of an algal canopy, wave action and dessication on predator feeding rates. Oecologia 34:17-35

Menge BA, Lubchenco J (1981) Community organization in temperate and tropical rocky intertidal habitats: prey refuges in relation to consumer pressure gradients. Ecol Monogr 51:429-450

Menge BA, Sutherland JP (1976) Species diversity gradients: synthesis of the roles of predation, competition, and temporal heterogeneity. Am Nat 110:351-369

Menge BA, Sutherland JP (1987) Community regulation: variation in disturbance, competition, and predation in relation to environmental stress and recruitment. Am Nat 130: 730-757

Mittelbach G, Chesson P (1987) Predation risk: indirect effects on fish populations. In: Kerfoot W, Sih A (eds) Predation: direct and indirect impacts on aquatic communities. University Press New England, Hanover, NH, p 315-332

Paine R (1980) Food webs: linkage, interaction strength and community infrastructure. J Anim Ecol 49:667-685

Persson L (1993) Predator-mediated competition in prey refuges: the importance of habitat dependent prey resources. Oikos 68:12-22

Persson L, Eklöv P (1995) Prey refuges affecting interactions between piscivorous perch and juvenile perch and roach. Ecology 76:70-81

Petraitis P (1990) Direct and indirect effects of predation, herbivory and surface rugosity on mussel recruitment. Oecologia 83:405-413

Editorial responsibility: Brian Helmuth, Columbia, South Carolina, USA
Polis GA, Hurd SD (1995) Extraordinarily high spider densities on islands: flow of energy from the marine to terrestrial food webs and the absence of predation. Proc Natl Acad Sci USA 92:4382-4386

> Qiu J, Tremblay R, Bourget E (2002) Ontogenetic changes in hyposaline tolerance in the mussels Mytilus edulis and $M$. trossulus: implications for distribution. Mar Ecol Prog Ser 228:143-152

Robles C, Sweetmen D, Eminike J (1990) Lobster predation on mussels: shore level differences in prey vulnerability and predator preference. Ecology 71:1564-1577

- Robles CD, Desharnais RA, Garza C, Donahue MJ, Martinez CA (2009) Complex equilibria in the maintenance of boundaries: experiments with mussel beds. Ecology 90: 985-995

> Rodgers K, Wing S (2008) Spatial structure and movement of blue cod (Parapercis colias) in Doubtful Sound, New Zealand, inferred from $\delta^{13} \mathrm{C}$ and $\delta^{15} \mathrm{~N}$. Mar Ecol Prog Ser 359:239-248

> Rosenberg R, Möller P (1979) Salinity stratified benthic macrofaunal communities and long term monitoring along the west-coast of Sweden. J Exp Mar Biol Ecol 37:175-203

Rutger S, Wing S (2006) Effects of freshwater input on shallow water infaunal communities in Doubtful Sound, New Zealand. Mar Ecol Prog Ser 314:35-47

Sih A (1992) Prey uncertainty and the balancing of antipredator and feeding needs. Am Nat 139:1052-1069

Sih A (1997) To hide or not to hide? Refuge use in a fluctuating environment. Trends Ecol Evol 12:375-376

Sih A, Crowley P, McPeek M, Petranka J, Strohmeier K (1985) Predation, competition, and prey communities: a review of field experiments. Annu Rev Ecol Syst 16:269-311

Sih A, Petranka J, Kats L (1988) The dynamics of prey refuge use: a model and tests with sunfish and salamander larvae. Am Nat 132:463-483

Sih A, Ziemba R, Harding KC (2000) New insights on how temporal variation in predation risk shapes prey behavior. Trends Ecol Evol 15:3-4

Smith F, Witman J (1999) Species diversity in subtidal landscapes: maintenance by physical processes and larval recruitment. Ecology 80:51-69

Stanton B, Pickard G (1981) Physical oceanography of the New Zealand fiords. NZOI Mem 88:3-37

Stickle W, Sabourin T (1979) Effects of salinity on the respiration and heart rate of the common mussel, Mytilus edulis L., and the black chiton, Katherina tunicata (Wood). J Exp Mar Biol Ecol 41:257-268

Tallis H, Wing S, Frew R (2004) Historical evidence for habitat conversion and local population decline in a New Zealand fjord. Ecol Appl 14:546-554

Witman J, Grange K (1998) Links between rain, salinity, and predation in a rocky subtidal community. Ecology 79: $2429-2447$

Submitted: January 14, 2010; Accepted: November 1, 2010 Proofs received from author(s): January 9, 2011 